\title{
ScIDoC
}

\author{
International Journal of Dentistry and Oral Science (IJDOS) \\ ISSN: $2377-8075$
}

\section{The Effect of Ferrule Design On Fracture Resistance and Failure Modes of Indirect Composite Endocrowns}

Research Article

\author{
Leila Payaminiya ${ }^{1 *}$, Maedeh Mohseni ${ }^{2}$, Ehsan Ghorbani ${ }^{3}$
}

${ }^{1}$ Assistant Professor, Department of Prosthodontics, Faculty of Dentistry, Tehran University of Medical Sciences, Tehran, Iran.

${ }^{2}$ Department of Prosthodontics, Faculty of Dentistry, Bushehr University of Medical Sciences, Bushehr, Iran.

${ }^{3}$ Department of Prosthodontics, Faculty of Dentistry, Bushehr University of Medical Sciences, Bushehr, Iran.

\section{Abstract}

Objective: The effect of ferrule design on fracture resistance of endocrowns is still unknown.

Material and Methods: Thirty extracted human mandibular third molars were randomly distributed into 2 groups ( $\mathrm{n}=15)$. In the first group, ferrule was not considered and the margins were prepared butt-joint. Second group received a circumferential $2 \mathrm{~mm}$ ferrule around the teeth. Conventional impressions were made. Endocrowns were fabricated of indirect composite, and then lutedwith resin cement. Then, all of the specimens were subjected to fracture resistance in a universal testing machine. Failure loads were recorded. Failure mode analysis was accomplished by $25 \mathrm{x}$ magnification optical microscope.The data were analyzed using Mann-Whitney $U$ test, and Chi-square test $(\mathrm{P}<0.05)$.

Results: Endocrowns with no ferrule showed a greater mean failure load $(2019.69 \mathrm{~N})$ than ferrule containing endocrowns $(836.89 \mathrm{~N})$. However, statistical analysis showed no significant difference between these two groups $(\mathrm{P}=0.349)$. Fractography analysis showed that only 4 out of 30 endocrowns exhibited catastrophic failure, and $73.3 \%$ of the failures were adhesive. And no significant difference was found between failure modes of the groups $(\mathrm{P}=0.242)$.

Conclusions: Ferrule design had no significant effect on failure loads and failure modes of endocrowns.

Keywords: Endodontically Treated Teeth; Endocrown; Fracture Resistance; Ferrule Effect.

\section{Introduction}

Prosthetic restoration of endodontically treated teeth with severe loss of coronal structure is often a clinical challenge [1], related to their higher rate of biomechanical complications when compared to vital teeth $[2,3]$. They have been traditionally restored with post and coresand full crowns. [4] Despite of the clinical success usingintraradicular posts, one disadvantage of using this technique is the additional reduction of sound tissue.[5] Furthermore, post-space preparation has the danger of root perforation and bacterial contamination [6]. Thanks to the advances in adhesive dentistry, endocrowns were suggested as an alternative to classical post and core approach [7]. Endocrown is a one-piece restoration which utilizes the pulp chamber surface to achieve stability and retention via adhesive bonding [8].
Endocrownsare more conservative, with much less chair time as compared to post and core technique. In addition, the functional stresses generated at the tooth/restoration interface could be better dissipated.[9] Depending on the elastic modulus of restorative material chosen, the restored tooth structure might be more rigid than the tooth (if using ceramics) or more similar to it (if usingindirect resin composites)[10] Moreover, resin compositesare repairable and less abrasive to opposite tooth structures in comparison to ceramics.[11]

The effect of ferrule preparation toincrease the fracture resistance of crowned teeth has been well described.[12, 13] However, the incorporation of ferrule design to the endocrown preparation has not been well assessed. In most studies,[14-20] endocrowns have a butt-joint margin. And there are a few studies [21-23] which have considered ferrule design in endocrown preparation. The purpose of present study was to determinethe effect offerrule

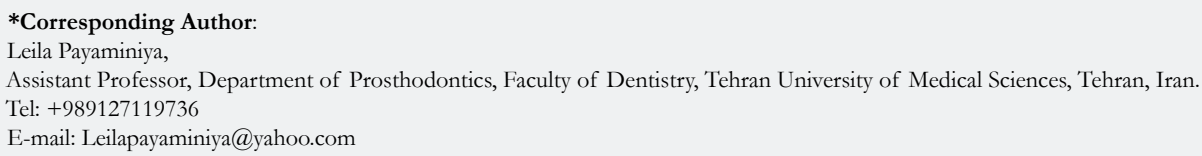

Citation: Leila Payaminiya, Maedeh Mohseni, Ehsan Ghorbani. The Effect of Ferrule Design On Fracture Resistance and Failure Modes of Indirect Composite Endocrowns. Int J Dentistry Oral Sci. 2021;8(8):3643-3647. doi: http://dx.doi.org/10.19070/2377-8075-21000745

Copyright: Leila Payaminiya 2021 . This is an open-access article distributed under the terms of the Creative Commons Attribution License, which permits unrestricted use, distribution and reproduction in any medium, provided the original author and source are credited. 
design on fracture resistance of indirect composite endocrowns. The null hypothesis was that there would be no difference infracture resistance between standard endocrown restorations and the ones with a prepared ferrule.

\section{Material and Methods}

\section{Teeth preparation}

Thirty recently extracted human mandibular third molars were evaluated in this study. Teeth selection was made according to the following principles: 1 . absence of caries and obvious fracture lines, 2. complete root formation, 3.approximately equal size of buccal-lingual, and mesial-distal dimensions and root length measured using digital calipers. They were stored in normal saline solution right after extraction. The roots of each tooth were coated with a layer of teflonband to simulate periodontal ligament. The specimens were then vertically mounted into auto-polymerizing acrylic resin (Repair \& Pour Resin, Medidentco, Hamburg, Germany) $3 \mathrm{~mm}$ below the CEJ in cubical molds.Coronal structure of each tooth was removed perpendicular to its long axis approximately $2 \mathrm{~mm}$ above the CEJ using a slow-speed diamond saw (Isomet, Buehler Ltd, Lake Bluff, IL, USA) with water spray. Endodontic access cavities were prepared using a high-speed handpiece (NSK, Japan) and diamond burs (Tizkavan, Tehran, Iran) using copious water spray. Canal orifices were enlarged using Gates-Glidden rotary instruments (Mani, Tochigi, Japan) and pulpal tissues were removed with rotary files (DentsplyMaillefer, Ballaigues, Switzerland).

Undercuts in the access cavities were eliminatedand occlusocervical internal taper ofthe pulp chamberswere prepared using a round-end taper diamond bur (Tizkavan, Tehran, Iran). The Internal line angles were also rounded. To achieve an identical $4 \mathrm{~mm}$ pulp chamber depth, pulpal floors were restored using a self-cure glass-ionomer(GC, Tokyo, Japan). The teeth were then randomly divided into 2 groups $(n=15)$. The first group did not receive additional preparation design, so margins were butt-joint $90^{\circ}$. The second group received a $2 \mathrm{~mm}$ circumferentially ferrule preparation design (Fig.1).A larger bur with the previous taper, and afiner particle sizewas used to polish the cervical band of the preparation. One researcher accomplished all preparations to standardize preparations.

\section{Endocrowns Fabrication}

Impressions were made using the simultaneous, dual-viscosity technique with extra light and extra heavy bodies of polyvinyl siloxane impression material(Panasil, Kettenbach,Germany) with metal stock trays.All impressions were poured in a type IV stone die (Tewerock, Kettenbach GmbH, Germany). The separating medium was applied inside the cavity, then indirect composite (Dialog Occlusal, Rosbach, Schutz, Germany) increments were condensed and cured layer by layer to form final contour of endocrown (Fig.2). Then endocrown was removed after initial curing before final light polymerization was applied.In order to make identical occlusal form and contour of the endocrowns, an index was made from the first endocrown and used for others. Also a dental gauge was used to standardize occlusal thickness $(8 \mathrm{~mm})$ of each endocrown.

\section{Cementation Procedures}

The intaglio surfaces of endocrowns were sandblasted with aluminum oxide particles for $10 \mathrm{~s}$. A silicone disclosing medium (Fit checker, GC, Tokyo, Japan) was used to assure proper seating of the endocrowns. Then they were cleansed in an ultrasonic cleaner (E-30H -Germany) for 5 minutes. The intaglio surfaces were etched with 37\% phosphoric acid gel (Morvabon, Iran) for 10 seconds.A thin layer of silane(Pulpdent, Watertown, MA, USA) was applied with a microbrush and allowed to dry for 60 seconds. The prepared tooth surfaces were selectively etched for $20 \mathrm{sec}-$ onds with 37\% phosphoric acid gel (Morvabon, Iran), followed by water rinsing and air drying. Endocrowns were lutedwith a self-adhesive self-etch resin luting agent(Panavia SA Cement Plus, Kuraray, Osaka, Japan).First they were tack cured for 5 seconds using a VLC unit (ART-L3 LED, Bonart, CA, USA), andexcess luting cement was removed from the margins.All surfaces then light cured for 20 seconds. These specimens were maintained in an incubator (ETUVE, Model 55.L, Pars Azma, Iran) at $37^{\circ} \mathrm{C}$ in $98 \%$ humidity for 24 hours.

\section{Loading}

24 hours after cementation, the fracture test was done in a universal testing machine(Zwick zo20, Germany) (Fig.3). A stainless-steel ball $(3.1 \mathrm{~mm}$ in diameter and $0.5-\mathrm{m}$ radius of curvature) with a cross-head speed of $0.5 \mathrm{~mm}$ per minute was applied perpendicular in the middle of the occlusal table. Force was applied until fracture. The maximum load to produce fracture was reported in Newtons $(\mathrm{N})$.

\section{Fractography}

Failure mode analysis was accomplished visually by $25 \mathrm{x}$ optical magnification microscope (BA210E, Motic, China). Fractures were divided into 4 groups: cohesive fracture (within the endocrown material), adhesive fracture (between the endocrown and tooth), restorable tooth fracture (above the CEJ), and catastrophic tooth fracture (below the CEJ). Fractures modes were confirmed by two researchers.

\section{Statistical analysis}

Data were analyzed using a statistical software (SPSS v22.0; IBM Corp, NY, USA). In addition to standard descriptive statistical calculations (mean and standard deviation), the Mann-Whitney Utest was carried out to compare the groups, and a Chi-square test wasapplied for qualitative data. The statisticalsignificance level was set at $\mathrm{P}<0.05$.

\section{Results}

The mean failure load of the groups is givenin Table 1. According to results, the mean failure load of the no ferrule group was higher than the ferrule containing group. However, Mann-Whitney U test showed no significantdifferences between them $(\mathrm{P}=0.349)$. The results of the groups' failure modes are listed in Table 2.Only 4 out of 30 endocrowns exhibited catastrophic failure, and $73.3 \%$ of the failures were adhesive. The Chi-square test revealed no significant differences between two groups $(\mathrm{P}=0.242)$. 
Table 1. Failure load results in Newton (N).

\begin{tabular}{|c|c|c|c|}
\hline & Mean \pm SD & Min & Max \\
\hline Ferrule containing group & $1836.89 \pm 475.81$ & 989.8 & 2441.16 \\
\hline No ferrule group & $2019.69 \pm 572.04$ & 948.06 & 2837.74 \\
\hline
\end{tabular}

Table 2. Failure mode results.

\begin{tabular}{|c|c|c|c|c|}
\hline & $\begin{array}{c}\text { Cohesive } \\
\text { fracture }\end{array}$ & $\begin{array}{c}\text { Adhesive } \\
\text { fracture }\end{array}$ & $\begin{array}{c}\text { Restorable tooth } \\
\text { fracture }\end{array}$ & $\begin{array}{c}\text { Catastrophic } \\
\text { tooth fracture }\end{array}$ \\
\hline Ferrule containing group & $320 \%$ & $1066.7 \%$ & $00 \%$ & $213.3 \%$ \\
\hline No ferrule group & $00 \%$ & $1280 \%$ & $16.7 \%$ & $213.3 \%$ \\
\hline
\end{tabular}

Figure 1. Endocrown preparation: a) with ferrule, b) without ferrule.
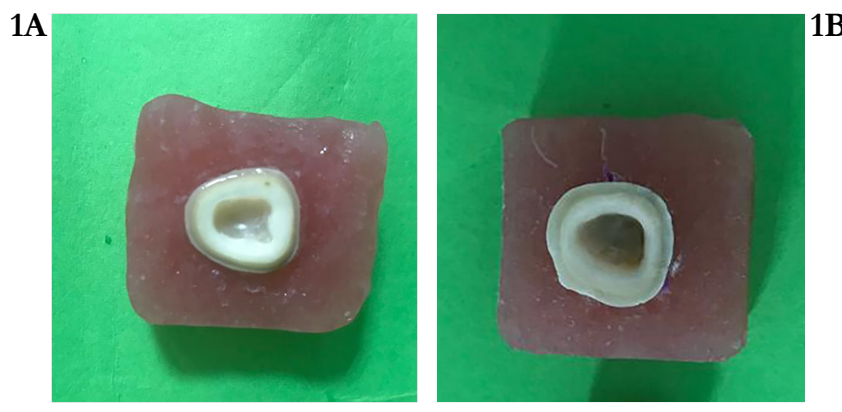

Figure 2. Indirect composite endocrown.

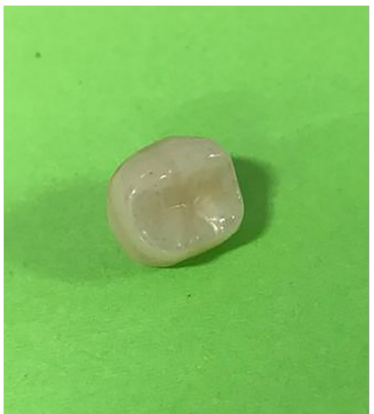

Figure 3. Fracture resistance testing using a universal testing machine.

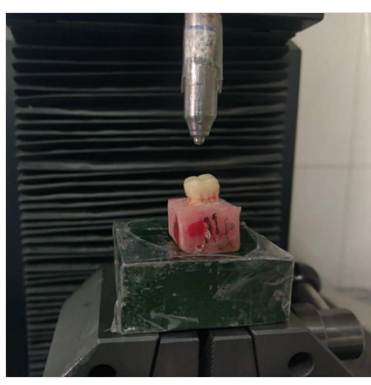

\section{Discussion}

The idea of a conservative cusp coverage restoration for severely damaged endodontically treated posterior teeth is not novel. Amalgam build-ups and onlays are based on this principle. In addition to this continuum, endocrown which is an esthetic and conservative option has been newly introduced. [24]

In this study, fracture resistance of indirect composite endocrowns was investigated. The results showed no significant difference between ferrule containing and no ferrule groups which confirms the null hypothesis. So adding ferrule design to the endocrown preparation does not seem effective to increase fracture
resistance.This might be attributed to several factors. One could be due to less enamel bonding when considering ferrule design. Although, Einhorn et al [21] showed ferrule preparation could increase available surface area for adhesive bonding due to addition of available dentin surface, it has been also reported that ferrule preparation might decrease enamel and dentin for bonding, [25] which may be ascribed to a more cervical finishing line.On the other hand, endocrowns due to their greater occlusal thickness (3-7 $\mathrm{mm}$ ) would show a higher fracture resistance to masticatory forces compared with conventional crowns. [26] Also, post core crowns consist of materials with different elastic moduli. Elastic modulus discrepancy between dentin, cement and restorative components could influence stress distribution. The more inter- 
faces exist, the less stress distribution is expected. While endocrown due to its mono-block nature would support more stress loading. [27]

In most studies related to endocrown, standard preparation (no ferrule) has been used.[14-20] However there are a few studies in which ferrule preparation is considered [21-23] including the research done by Einhorn et al [21] in 2017. Contrary to the results of the present study, they showed that ferrule-containing endocrowns had significantly greater failure loads than standard endocrowns. However, computed failure stress according to the available surface area for bonding was not significantly different between the groups [21]. By considering the definition of stress as "the ratio of applied force to a cross section area (stress = F/A)", their result might be attributed to the fact that ferrule preparation could increase available surface area for adhesive bonding. So, it seems that the numerator and the denominatorof the fraction are appropriately increased.

Abdel-Aziz and Abo-Elmagd [22] recommended that the endodontically treated mandibular premolars should not be restored with endocrown in the absence of ferrule.Their study showed that presence of ferrule increased the fracture resistance of endodontically treated mandibular premolars than those without ferrule. It is inconsistent with current study result.This difference may be due to different type of teeth (premolars versus molars) used.As Bindl and Mörmann [28] evaluated the survival rate of ceramic restorations with different preparation designs cemented to premolars and molars. They observed more failures of endocrowns in premolarsthan molars. This would be due to the smaller size of pulp chamber in premolars, which reduces the surface for adhesive bonding.

Belleflame et al [23] evaluated 99 documented cases of endocrowns for 10 years. They reported that survival and success rates respectivelywere $99.0 \%$ and $89.9 \%$. Due to the small number of failures, no statistical relationship could be found with clinical parameters like ferrule design $(54.5 \%$ of cases). This result was somehow in agreement with the current study, however it should be noted that in the mentioned study only the buccal ferrule was designed. The other notable finding Belleflame et al [23] reported was that no debonding was detected on premolars, while they could be subjected to non-axial functional loading, which could result in more failures compared to molars, as revealed by Bindl et al.[28]

Lithium disilicate glass ceramic and micro hybrid resin composite materials are broadly used for indirect restorations. Microhybrid indirect composites have the advantages of lower cost and better stress-absorbing properties.[11] In this study Dialog occlusal laboratory composite was used. Mean failure load (2019.69 N) was close to the mean failure load of composite endocrowns madeof Gradia $(2366.50 \mathrm{~N})$ and Solidex $(2222.14 \mathrm{~N})$ in the study by Altier et al.[29]. It should be noted that this mean failure load was well above the maximum bite force in the molars (847 N).[30]

In the study of M. Altier et al, [29] as well as Gungor et al,[31] it was shown that lithium disilicate endocrowns have higher fracture resistance than composite endocrowns. However, El Damanhoury et al [32] investigated the fracture resistance of three types of endocrowns made of lithium disilicate, feldspathic porcelain, and multiphase resin composite (Lava Ultimate). They found out that resin composite showed higher fracture resistance than the other groups. The different results of these studies are likely due to the differences between the structures of the composites used, testing methods (diameter and velocity of piston, and angle of load application) or the cementation techniques.

In this study, there was no significant difference in failure modebetween ferrule containing and no ferrule groups. Only 4 out of 30 endocrowns had catastrophic failure, and most of failures (73.3\%) were adhesive. However, in Einhorn et al's study, [21] a high percentage of endocrowns catastrophically failed, regardless of the presence or absence of ferrule. This might be because ofdifferent type of material (IPS e.max CAD) used to fabricate endocrowns, and thus higher mismatch between elastic moduli of tooth and restoration.

The present in vitro study had some limitations and did not well simulate the clinical situation. For instance, thermocycling was not performed. However, in the dental literature the results on the effect of artificial aging with thermocyclingon adhesion is still controversial. While some authors have notreportedany significant effect, others have.[33-36] So, the clinicalrelevancy of such aging methods has to be confirmedin future clinical studies. Future studies are further recommended to include dynamic loading, to efficiently simulate intraoral forces.

\section{Conclusion}

Based on results of this study, there was no significant difference in failure loads and failure modes of endocrowns with or without ferrule.The mean fracture resistance of the composite endocrowns was much greater than the reported maximal bite force in molar region. And a high percentage $(73.3 \%)$ of the fractures was categorized as adhesive fractures, so did not involve the tooth structure.

Ethical approval: This article does not contain any studies with human participants or animals performed by any of the authors.

Funding: The work was supported by the Department of Prosthodontics, Bushehr University of Medical Sciences, Iran.

\section{References}

[1]. Zhu Z, Dong XY, He S, Pan X, Tang L. Effect of Post Placement on the Restoration of Endodontically Treated Teeth: A Systematic Review. Int J Prosthodont. 2015 Sep-Oct;28(5):475-83. Pubmed PMID: 26340006.

[2]. Fennis WM, Kuijs RH, Kreulen CM, Roeters FJ, Creugers NH, Burgersdijk RC. A survey of cusp fractures in a population of general dental practices. Int J Prosthodont. 2002 Nov-Dec;15(6):559-63. Pubmed PMID: 12475162.

[3]. Llena-Puy MC, Forner-Navarro L, Barbero-Navarro I. Vertical root fracture in endodontically treated teeth: a review of 25 cases. Oral Surg Oral Med Oral Pathol Oral Radiol Endod. 2001 Nov;92(5):553-5. Pubmed PMID: 11709692.

[4]. Hussain SK, McDonald A, Moles DR. In vitro study investigating the mass of tooth structure removed following endodontic and restorative procedures. J Prosthet Dent. 2007 Oct;98(4):260-9. Pubmed PMID: 17936125.

[5]. Lazari PC, Oliveira RC, Anchieta RB, Almeida EO, Freitas Junior AC, Kina $S$, et al. Stress distribution on dentin-cement-post interface varying root canal and glass fiber post diameters. A three-dimensional finite element analysis based on micro-CT data. J Appl Oral Sci. 2013 Nov-Dec;21(6):511-7. Pubmed PMID: 24473716.

[6]. Ferrari M, Vichi A, Grandini S. Efficacy of different adhesive techniques on bonding to root canal walls: an SEM investigation. Dent Mater. 2001 Sep;17(5):422-9. Pubmed PMID: 11445210. 
[7]. Pissis P. Fabrication of a metal-free ceramic restoration utilizing the monobloc technique. Pract Periodontics Aesthet Dent. 1995 Jun-Jul;7(5):83-94. Pubmed PMID: 7548896.

[8]. Bindl A, Mörmann WH. An up to 5-year clinical evaluation of posterior in-ceram CAD/CAM core crowns. Int J Prosthodont. 2002 SepOct;15(5):451-6. Pubmed PMID: 12375459.

[9]. Chang CY, Kuo JS, Lin YS, Chang YH. Fracture resistance and failure modes of CEREC endo-crowns and conventional post and core-supported CEREC crowns. Journal of Dental Sciences. 2009 Sep 1;4(3):110-7.

[10]. Ramírez-Sebastià A, Bortolotto T, Cattani-Lorente M, Giner L, Roig M, Krejci I. Adhesive restoration of anterior endodontically treated teeth: influence of post length on fracture strength. Clin Oral Investig. 2014;18(2):54554. Pubmed PMID: 23604697.

[11]. Magne P, Schlichting LH, Maia HP, Baratieri LN. In vitro fatigue resistance of CAD/CAM composite resin and ceramic posterior occlusal veneers. J Prosthet Dent. 2010 Sep;104(3):149-57. Pubmed PMID: 20813228.

[12]. Ma PS, Nicholls JI, Junge T, Phillips KM. Load fatigue of teeth with different ferrule lengths, restored with fiber posts, composite resin cores, and allceramic crowns. J Prosthet Dent. 2009 Oct;102(4):229-34. Pubmed PMID: 19782825.

[13]. Pereira JR, de Ornelas F, Conti PC, do Valle AL. Effect of a crown ferrule on the fracture resistance of endodontically treated teeth restored with prefabricated posts. J Prosthet Dent. 2006 Jan;95(1):50-4. Pubmed PMID: 16399275 .

[14]. Biacchi GR, Basting RT. Comparison of fracture strength of endocrowns and glass fiber post-retained conventional crowns. Oper Dent. $2012 \mathrm{Mar}-$ Apr;37(2):130-6. Pubmed PMID: 21942234.

[15]. Darwish HA, Morsi TS, El Dimeery AG. Internal fit of lithium disilicate and resin nano-ceramic endocrowns with different preparation designs. Future Dental Journal. 2017 Dec 1;3(2):67-72.

[16]. Gregor L, Bouillaguet S, Onisor I, Ardu S, Krejci I, Rocca GT. Microhardness of light- and dual-polymerizable luting resins polymerized through 7.5-mm-thick endocrowns. J Prosthet Dent. 2014 Oct;112(4):942-8. Pubmed PMID: 24767899.

[17]. Rocca GT, Daher R, Saratti CM, Sedlacek R, Suchy T, Feilzer AJ, et al. Restoration of severely damaged endodontically treated premolars: The influence of the endo-core length on marginal integrity and fatigue resistance of lithium disilicate CAD-CAM ceramic endocrowns. J Dent. 2018 Jan;68:4150. Pubmed PMID: 29107134

[18]. Rocca GT, Sedlakova P, Saratti CM, Sedlacek R, Gregor L, Rizcalla N, et al. Fatigue behavior of resin-modified monolithic CAD-CAM RNC crowns and endocrowns. Dent Mater. 2016 Dec;32(12):e338-e350. Pubmed PMID: 27671466

[19]. Shin Y, Park S, Park JW, Kim KM, Park YB, Roh BD. Evaluation of the marginal and internal discrepancies of CAD-CAM endocrowns with different cavity depths: An in vitro study. J Prosthet Dent. 2017 Jan;117(1):109-115. Pubmed PMID: 27460311.

[20]. Zarone F, Sorrentino R, Apicella D, Valentino B, Ferrari M, Aversa R, et al. Evaluation of the biomechanical behavior of maxillary central incisors restored by means of endocrowns compared to a natural tooth: a 3D static linear finite elements analysis. Dent Mater. 2006 Nov;22(11):1035-44. Pubmed PMID: 16406084.
[21]. Einhorn M, DuVall N, Wajdowicz M, Brewster J, Roberts H. Preparation Ferrule Design Effect on Endocrown Failure Resistance. J Prosthodont. 2019 Jan;28(1):e237-e242. Pubmed PMID: 28985446.

[22]. Abdel-Aziz M, Abo-Elmagd AA. Effect of endocrowns and glass fiber postretained crowns on the fracture resistance of endodontically treated premolars. Egypt Dent J. 2015 Jul;61(3203):3210-6.

[23]. Belleflamme MM, Geerts SO, Louwette MM, Grenade CF, Vanheusden AJ, Mainjot AK. No post-no core approach to restore severely damaged posterior teeth: An up to 10-year retrospective study of documented endocrown cases. J Dent. 2017 Aug;63:1-7. Pubmed PMID: 28456557.

[24]. Carlos RB, Thomas Nainan M, Pradhan S, Roshni Sharma, Benjamin S, Rose R. Restoration of endodontically treated molars using all ceramic endocrowns. Case Rep Dent. 2013;2013:210763. Pubmed PMID: 24455318.

[25]. Skupien JA, Luz MS, Pereira-Cenci T. Ferrule Effect: A Meta-analysis. JDR Clin Trans Res. 2016 Apr;1(1):31-39. Pubmed PMID: 30931698.

[26]. Motta AB, Pereira LC, Duda FP, Anusavice KJ. Influence of substructure design and occlusal reduction on the stress distribution in metal ceramic complete crowns: 3D finite element analysis. J Prosthodont. 2014 Jul;23(5):3819. Pubmed PMID: 24417730.

[27]. Tay FR, Pashley DH. Monoblocks in root canals: a hypothetical or a tangible goal. J Endod. 2007 Apr;33(4):391-8. Pubmed PMID: 17368325.

[28]. Bindl A, Richter B, Mörmann WH. Survival of ceramic computer-aided design/manufacturing crowns bonded to preparations with reduced macroretention geometry. Int J Prosthodont. 2005 May-Jun;18(3):219-24. Pubmed PMID: 15945309.

[29]. Altier M, Erol F, Yildirim G, Dalkilic EE. Fracture resistance and failure modes of lithium disilicate or composite endocrowns. Niger J Clin Pract. 2018 Jul;21(7):821-826. Pubmed PMID: 29984710.

[30]. Waltimo A, Könönen M. A novel bite force recorder and maximal isometric bite force values for healthy young adults. Scand J Dent Res. 1993 Jun;101(3):171-5. Pubmed PMID: 8322012.

[31]. Bankoğlu Güngör M, Turhan Bal B, Yilmaz H, Aydin C, Karakoca Nemli S. Fracture strength of CAD/CAM fabricated lithium disilicate and resin nano ceramic restorations used for endodontically treated teeth. Dent Mater J. 2017 Mar 31;36(2):135-141. Pubmed PMID: 28111383.

[32]. El-Damanhoury HM, Haj-Ali RN, Platt JA. Fracture resistance and microleakage of endocrowns utilizing three CAD-CAM blocks. Oper Dent. 2015 Mar-Apr;40(2):201-10. Pubmed PMID: 25268039.

[33]. De Munck J, Mine A, Poitevin A, Van Ende A, Cardoso MV, Van Landuyt $\mathrm{KL}$, et al. Meta-analytical review of parameters involved in dentin bonding. J Dent Res. 2012 Apr;91(4):351-7. Pubmed PMID: 22173327.

[34]. Kumbuloglu O, Lassila LV, User A, Toksavul S, Vallittu PK. Shear bond strength of composite resin cements to lithium disilicate ceramics. J Oral Rehabil. 2005 Feb;32(2):128-33. Pubmed PMID: 15641979.

[35]. Leloup G, D'Hoore W, Bouter D, Degrange M, Vreven J. Meta-analytic review of factors involved in dentin adherence. Journal of Dental Research. 1998;77:944.

[36]. Nagai T, Kawamoto Y, Kakehashi Y, Matsumura H. Adhesive bonding of a lithium disilicate ceramic material with resin-based luting agents. J Oral Rehabil. 2005 Aug;32(8):598-605. Pubmed PMID: 16011639. 